\title{
ENHANCING COASTAL RESILIENCY OF HYPOTHETICAL LAND RECLAMATION SCENARIOS WITH MANGROVE FOREST AND OYSTER REEF ASSESSED BY ADCIRC AND SWAN STORM SURGE MODEL
}

\author{
J. Rayo $^{1}$, J. Seriosa ${ }^{2}$, J. Villa Juan ${ }^{2}$, V. P. Boñgolan ${ }^{1}$ \\ ${ }^{1}$ Department of Computer Science, University of the Philippines Diliman, Quezon City, Philippines 1101 \\ ${ }^{2}$ College of Architecture, University of the Philippines Diliman, Quezon City, Philippines 1101 \\ (jbrayo, jbseriosa1, jvvillajuan1, vabongolan)@up.edu.ph
}

KEY WORDS: Land reclamation, Crenulate bay, Mangrove, Oyster reef, Storm surge, ADCIRC, SWAN, Philippines.

\begin{abstract}
:
This study aims to assess the effectiveness of mangrove forests and oyster reefs on reducing the damages from typhoons in hypothetical land reclamation scenarios in Atimonan, Philippines. Storm surge simulations were ran using ADCIRC and SWAN coupled model on the local government unit's (LGU) land reclamation plan and the proposed crenulate bay reclamation plan, both with concrete seawall, mangrove forests and oyster reefs. Inputs to the model include modified topography and bathymetry, coastline, land cover, typhoon Durian data and tidal potential constituents. Simulations show that the crenulate bay reclamation plan is better by $39.15 \%$ than the LGU's land reclamation plan on reducing typhoon winds and storm surge inundation extent induced by Typhoon Durian. However, this advantage comes with an additional implementation cost of $11.02 \%$. This study is envisioned to help the land reclamation project of Atimonan LGU to be resilient against typhoon winds and coastal inundation.
\end{abstract}

\section{INTRODUCTION}

The Province of Quezon in the Philippines, where the Town of Atimonan is located, has 45 mangrove species and the country's most botanically diverse in terms of mangrove forests (Orinday, 2019). Aside from providing habitat, spawning ground and nursery for marine species (Giri, et. al., 2010), mangrove forests also help in stabilizing shorelines and mitigate devastating impacts of tropical storms and tsunamis.

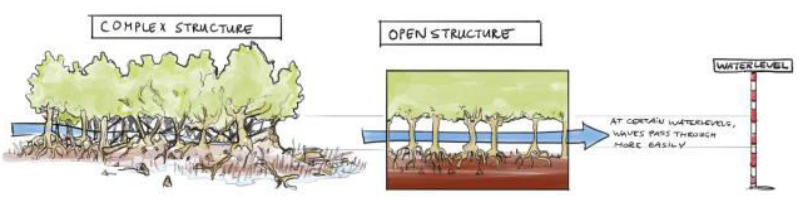

Figure 1. Mangroves reduce the height and energy of wind as well as waves as they pass through their roots and branches which are tangled above-ground (Spalding et. al., 2014).

Mangroves with complex structure (see Figure 1) of dense aerial roots and low branches with various species of different ages and sizes are more effective in reducing wave heights by half after 100 meters through (Spalding, et. al., 2014). While mangrove afforestation appears to be possible (Saenger and Siddiqi, 1993), its survival is sensitive to location, salinity, water level, light intensity, temperature and $\mathrm{pH}$ values. Conditions for adaptability and survival of R. mucronata, R. apiculata, R. stylosa, S. caseolaris, A. marina and N. fruticans species are further discussed by Melana, (1993), Amaliya, et. al. (2017), Hoppe-Speer, et. al. (2011), Ye, et. al. (2005) and Hossain \& Islan (2015).

The use of oyster reefs for shoreline protection has also increased in popularity because of their ability to adapt to environmental changes, control shoreline erosion and improve water quality (Grabowski, et. al., 2012). Oyster reefs are responsible for significant drop in wave height and energy during severe storms (Brandon, et. al., 2016). It can recover quickly from storm events (Livingston, et. al., 1999), reduce wave energy and provide better sediment stability at 30 meters in width (Chowdhury et al., 2019). Bivalve reefs also serve as a natural solution that promotes biodiversity, coastal protection, and climate change mitigation (Ysebaert, et. al., 2018).

The use of natural coastal protection such as biogenic reefs and vegetation (Spalding, et. al., 2014) has kindled increasing interest in the study of living shorelines - also referred to as natured-based shorelines or green shorelines. This can also be implemented in hybrid, combining natural and artificial barriers for coastal defense (Sutton-Grier, et. al., 2015). As of now there are only few data that quantifies the effectiveness of hybrid coastal protection approaches (Morris, et. al., 2019), thus the need to study this further.

The crenulate bay (see Figure 2) is a coast with constrained sediment supply between two erosion-resistant points (headlands or coastal structures) and will adjust its shape to an orientation that is perpendicular to the main wave direction. It is the stable shape of the coastline since the breaker line is parallel to the shore along the whole bay due to refraction and diffraction of the incoming waves (Reeve, et. al., 2004). The natural shape of this type of shoreline is often a log-spiral. It is a useful approach in predicting shoreline changes for future coastal management strategies in medium- or long-term plans.
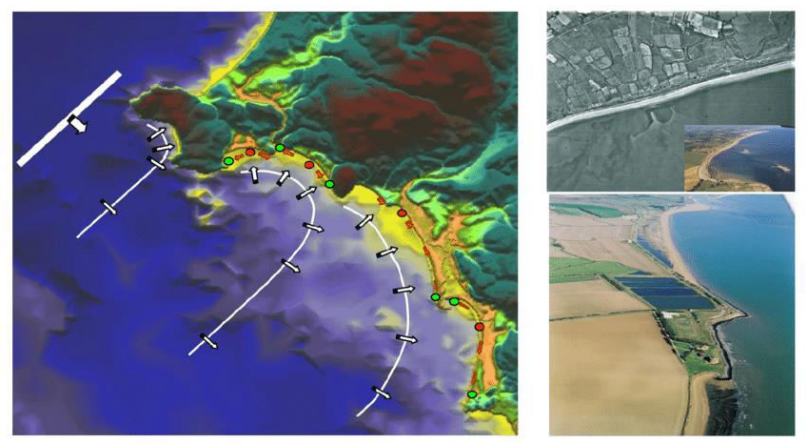

Figure 2. Examples of crenulate bay (Brew, et. al. 2010). 
The Atimonan City Center is used for commercial, residential, recreational and utility purposes. Other areas with gentle slopes are already occupied, and it is surrounded by mountainous terrain with steep slopes unsuitable for construction (see Figures 3 and 4). To address this situation, the local government unit (LGU) has planned to reclaim a portion of the coastal area as part of their proposed town expansion project. The Town Expansion Development program involves the reclamation of 24.5-hectare portion of Lamon Bay to extend the City Center and provide ample space to modern infrastructure that will bring better government services to the local community. Like any coastal town, Atimonan is also susceptible to coastal flooding, sea level rise, storm surge and tsunami.

Land reclamation is increasingly adopted to address the need for residential and industrial areas in many Southeast Asian cities (Nadzir, et. al., 2014). It needs to be examined thoroughly to minimize its adverse effects on the surrounding environment. The intrusion of saltwater to groundwater on dredged areas may increase the salinity of soil and groundwater making the latter unsuitable for residential and agricultural purposes. Land reclamation may also result in sedimentation which affects water quality and increases the risk of flooding and storm surge. Forest wetlands, when removed, may have negative impacts on human health and increase the disease spread since they act as air filter. Lastly, pollution from human activity on the reclaimed land may damage and erode the existing biodiversity (Nadzir, et. al., 2014).
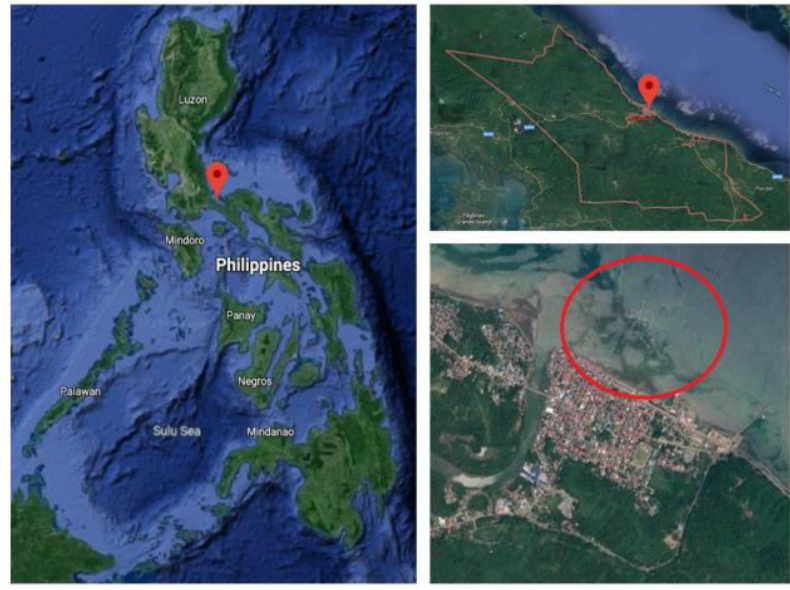

Figure 3. Satellite images of Atimonan, Philippines (taken from Google Earth Pro) located on $13.9985^{\circ} \mathrm{N}, 121.9195^{\circ} \mathrm{E}$.

Encircled area represents the potential area to be reclaimed, and the city center is located on South of it.

The ADCIRC model is developed for solving free surface circulation and transport problems in two or three dimensions. The surface velocity is solved from the momentum equations, while the surface elevation is solved from the generalized wave continuity equation. The equations are discretized in space using finite element method and in time using finite difference method. Finite element method to allows the use of highly flexible unstructured grids on complex coastline and bathymetry and enables high resolution modelling of localized surface flow on complex regions while minimizing computational cost (Luettich, et. al., 1992). The SWAN model can compute random short-rested wind-generated waves in coastal regions and inland waters. Other features include the computation of three and four-wave interaction, whitecapping, bottom friction, depthinduced breaking, dissipation due to aquatic vegetation, turbulent flow, viscous fluid mud, transmission through and reflection against obstacles and diffraction (Xie, et. al., 2016). When coupled together, ADCIRC and SWAN is proved to be effective in modelling wave propagation and storm surges to coastal areas (Hope, et. al., 2008).

Typhoon Durian is one of the strongest typhoons that hit the study area. It entered the Philippine Area of Responsibility on 28 November 00:00 UTC, made several landfalls then exited on 02 December 18:00 UTC. Favorable environment conditions allowed it to become a super typhoon with maximum sustained winds of $225 \mathrm{kph}$ on 29 November 06:00 UTC. It left at least 715 people dead, 2,174 injured and 764 missing. Damages to agriculture and infrastructure were estimated at \$124 million (United Nations Office for the Coordination of Human Affairs, 2016).

In this study, the effectiveness of combining mangroves, oyster reefs and concrete seawall is investigated for reducing the damages from tropical storms. Hypothetical land reclamation scenarios were compared, namely the LGU plan (see Figure 8) and the crenulate bay plan (see Figure 9). Storm winds and surge induced by typhoon Durian will be simulated using ADCIRC and SWAN models. Comparative analysis is done on both reclamation scenarios to justify which one is better in reducing typhoon winds and coastal inundation. The results of the study will help the Atimonan LGU to gather better insights on their proposed land reclamation project.

\section{METHODOLOGY}

\subsection{Hypothetical land reclamation scenarios}

The crenulate bay was derived from the analysis of the coastline and existing coastal wave behavior observed during the site visit. From aerial photos, it was observed that the waves on the offshore are coming from the northeast. From the historical satellite images, there were no noticeable changes along the shore of the City Center until 2006 when sediments were accumulated around the mouth of the river going to the sea. Sediment accumulation is observed during the site visit (see Figure 4).

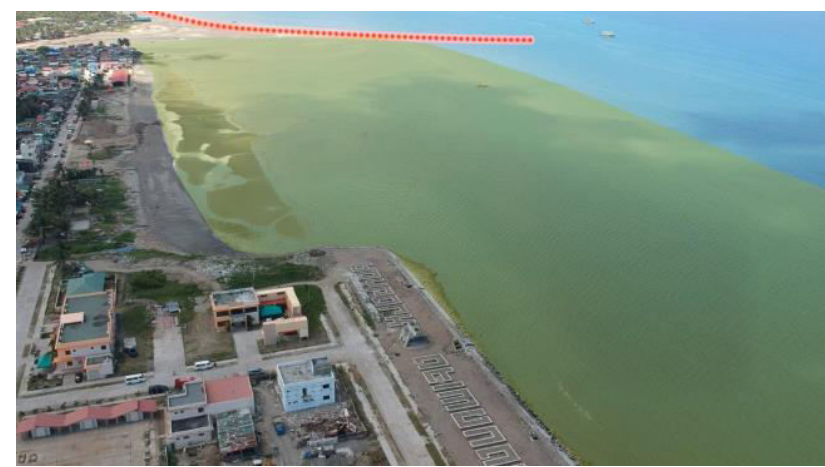

Figure 4. Aerial photo of the study area. Yellow area highlights the accumulation of sand sediments.

The shape of the proposed crenulate bay (see Figure 5) follows the curve of the shoreline in the Northwest and Southeast portions of the study area. It is already forming along the foreshore, coinciding with the sand sediments accreted nearshore. 

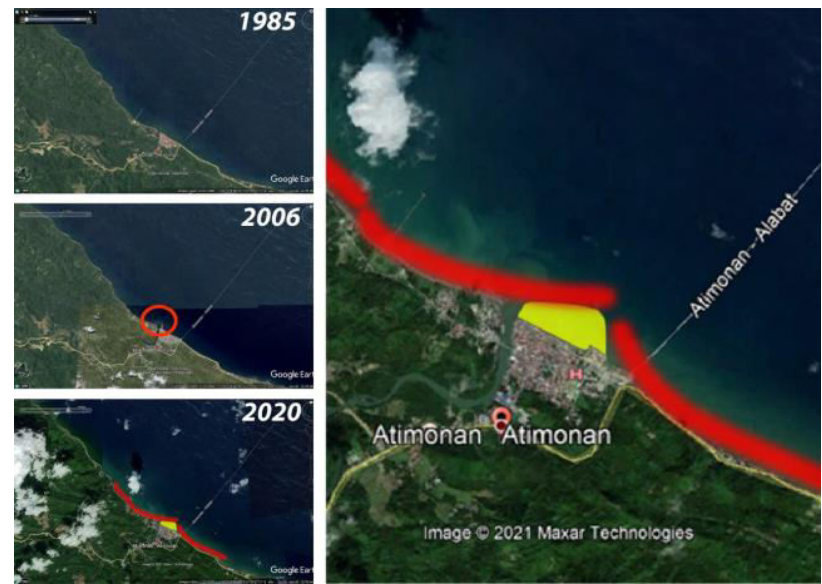

Figure 5. Historical satellite images of study area taken from Google Earth Pro. The proposed crenulate bay is highlighted in yellow, while the red line illustrates the shape where the crenulate bay was derived.

Photo documentation and purposive sampling was used to determine different mangrove species and its environmental conditions present in the study area. Digital meter and refractometer were used to measure soil $\mathrm{pH}$, soil temperature, water salinity and water temperature. The mangrove species (and tolerable salinity concentration) identified on the site visit (see Figure 6) were R. apiculata (0-30 ppt), R. mucronata (0-30 ppt), S. caseolaris (0-30 ppt), A. marina (5-35 ppt), R. stylosa (0-50 ppt), and N. fruticans (1-9 ppt).

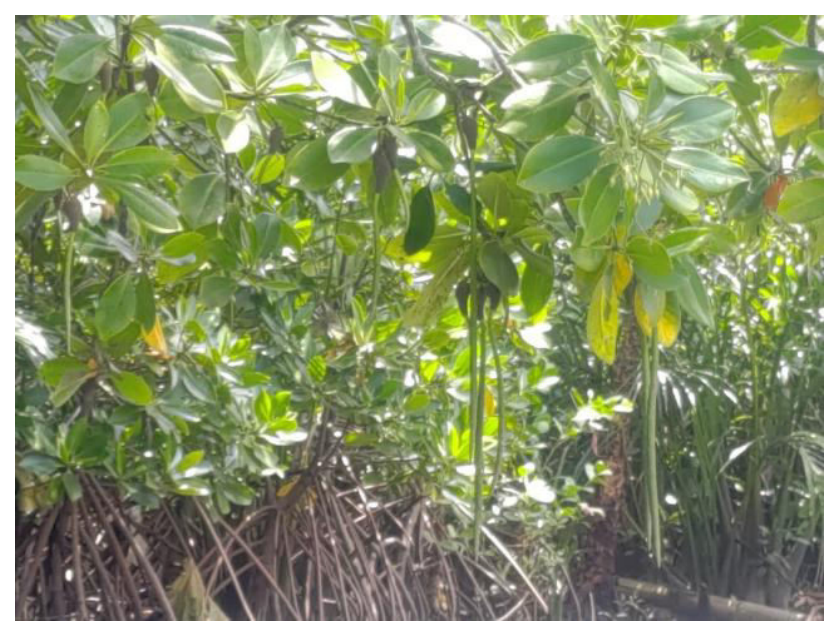

Figure 6. Photo of an R. apiculata mangrove forest captured during the site visit.

It was also observed that water salinity concentration is gradually increasing from the river leading to the sea (see Figure 7). Consequently, mangrove species zonation for both reclamation scenarios is based on water salinity concentration and temperature assessment during the site visit. Species with lesser tolerance to water salinity are positioned near the mouth of the river where salinity concentration is low.

The width of the oyster reefs and mangrove plantation was set to 50 meters (Chowdhury et al., 2019) and 100 meters (Spalding, et. al., 2014) respectively to ensure effective reduction of typhoon winds and wave energy. The built-up area shall be surrounded by a concrete seawall, and the soil used for the reclamation is assumed to be the same as where mangroves currently thrive.

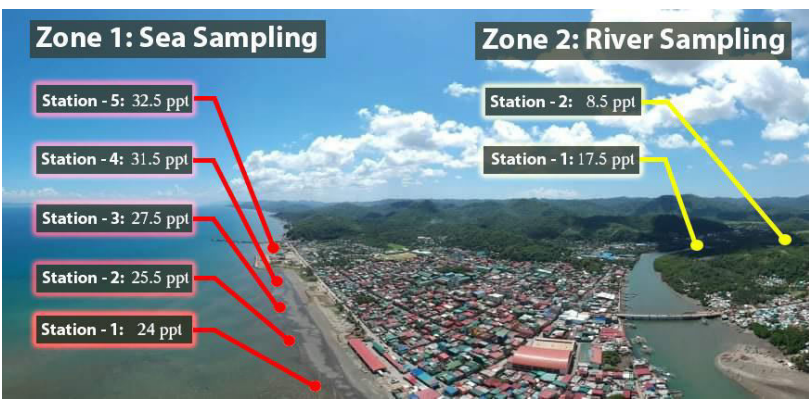

Figure 7. Measured salinity concentration of different locations on the river and nearshore, where the reclamation shall be done.

On both reclamation scenarios, the combined cost of mangrove forest and oyster reefs only account for $0.03 \%$ of the estimated total cost. Furthermore, the estimated total cost of the crenulate bay plan is $11.02 \%$ more expensive than the LGU plan, as supported by Tables 1 and 2 .

\begin{tabular}{|l|l|l|}
\hline LGU plan & Area (in hectares) & Cost (in Php) \\
\hline Land reclamation & 24.5 & $2,627,877,866$ \\
Mangrove forest & 12.6 & 628,362 \\
Oyster reef & 6.53 & 162,826 \\
TOTAL & $\mathbf{4 3 . 6 3}$ & $\mathbf{2 , 6 2 8 , 6 6 9 , 0 5 4}$ \\
\hline
\end{tabular}

Table 1. Estimated figures for implementing the LGU plan.

\begin{tabular}{|l|l|l|}
\hline Crenulate bay plan & Area (in hectares) & Cost (in Php) \\
\hline Land reclamation & 27.2 & $2,917,480,733$ \\
Mangrove forest & 14 & 698,180 \\
Oyster reef & 7.25 & 180,779 \\
TOTAL & $\mathbf{4 8 . 4 5}$ & $\mathbf{2 , 9 1 8 , 3 5 9 , 6 9 2}$ \\
\hline
\end{tabular}

Table 2. Estimated figures for implementing the crenulate bay plan.

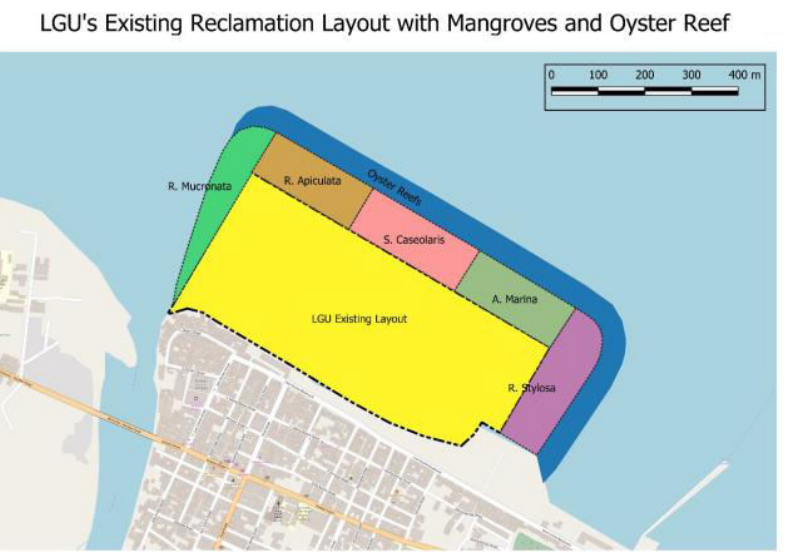

Figure 8. LGU reclamation plan. Yellow zone is for government, commercial and recreational use, blue zone is for oyster reefs, while the remaining zones are for different species of mangroves. 


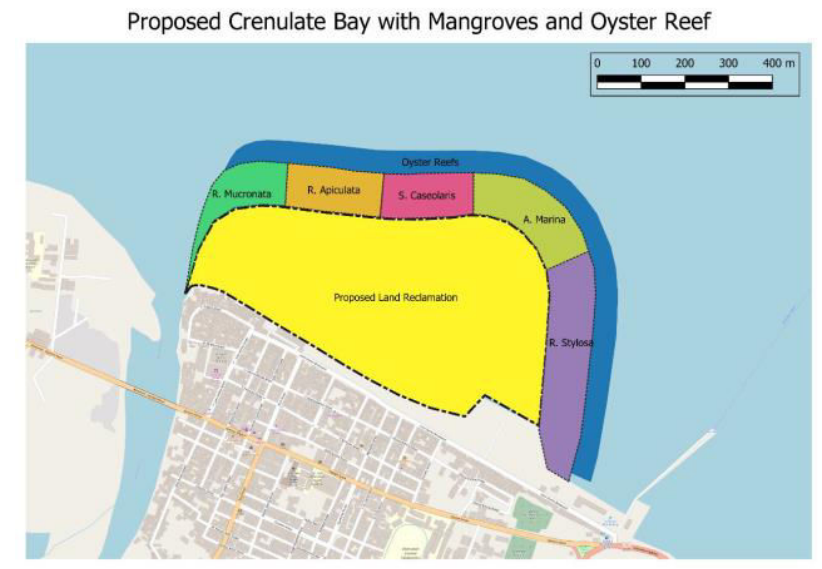

Figure 9. Crenulate bay reclamation plan. Zoning is similar to the LGU reclamation plan (see Figure 7).

\subsection{Data preparation}

The coastline, land cover data and IFSAR 5-meter digital elevation model provided by Philippines' National Mapping Authority (NAMRIA) were modified using Google Earth Pro and Quantum GIS to accommodate the requirements of both reclamation plans. The area to be reclaimed and its seawall were assigned as built-up areas and are 2 meters and 2.3 meters above mean sea level, respectively. The area for mangroves and oyster reefs was assigned to 0 meters above mean sea level, as mangroves need to be in the intertidal zone for them to thrive. Additionally, the bathymetry data used was GEBCO 30 arcsecond global grid (Weatherall, et. al., 2015).

The OceanMesh2D software was used to generate twodimensional unstructured mesh for coastal ocean circulation models from the modified DEMs, bathymetry, elevation contours and coastline. The vertices are determined using a force balance algorithm and mesh improvement strategies to improve the worst-case mesh quality (Roberts, et. al., 2019). To save computational resources, areas with elevation of at least 15 meters above mean sea level were excluded in the mesh generation process. Mesh size constraints were set to determine the possible largest length of an element. For the feature mesh size, only three (3) vertices per straight width of shoreline feature was set. The wavelength mesh size was set as 60 elements to resolve the $M_{2}$ tidal wavelength. The topographic length mesh size parameter was set to 30 to adapt to steeper slopes. After applying the mesh size constraints, the mesh size is further refined for numerical stability.

Mesh size are set not to be larger than its neighbors by $20 \%$ to enable smooth mesh size gradation. Additionally, the mesh was set to be computationally stable at 10 -second timestep by applying CFL limiting. The resulting mesh (see Figure 10) has 1,391 vertices and 776 elements with open ocean, mainland and island boundaries automatically generated. OceanMesh2D enables flexible, automatic and reproducible mesh generation process to provide high-quality unstructured meshes for realistic modelling of large-scale storm surge events in complex land features and water bodies (Roberts, et. al., 2019).

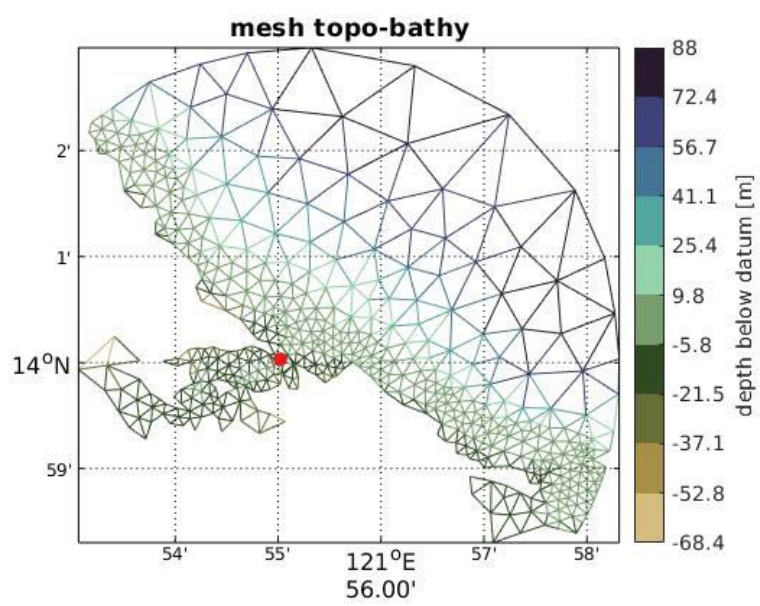

Figure 10. Unstructured mesh for crenulate bay reclamation plan generated using OceanMesh2D, with visualization of topography and bathymetry. The location of hypothetical land reclamation is marked red.

\subsection{Storm surge simulation}

Physically realistic parameters were included in the storm surge model to improve the accuracy of the simulation (Mattocks and Forbes, 2008). The directional surface roughness length parameter modulates the wind speed and applies forest canopy sheltering depending on land cover. In heavily canopied forests such as mangrove forests, there is little momentum transfer from the wind field to the water column, so no wind stress is applied on the water surface. Spatially varying Manning's n roughness values were assigned as well, with built up areas, mangrove forests and oyster reefs having $0.15,0.1$ and 0.015 , respectively. Quadratic friction coefficient at sea floor and horizontal eddy viscosity in sea water with respect to depth were also applied in the storm surge model.

Eight (8) primary $\left(M_{2}, S_{2}, N_{2}, K_{2}, K_{1}, O_{1}, P_{1}, Q_{1}\right)$, two (2) longperiod $\left(M_{f}, M_{M}\right)$ and five (5) non-linear $\left(M_{4}, M S_{4}, M N_{4}, 2 N_{2}, S_{1}\right)$ tidal harmonic constituents were extracted from TPXO9 model (Egbert and Erofeeva, 2002) to provide initial and boundary conditions for surface elevation and velocity. Typhoon Durian wind data was obtained from Joint Typhoon Warning Center and interpolated to the simulation using generalized asymmetric Holland wind model (Mattocks and Forbes, 2008). For the wind drag model, the Powell model was used, with maximum wind drag of 0.003 . The spherical coordinate system was used to account for the Coriolis effect.

The simulation timeframe was set to 26 November 00:00 UTC to 2 December 2006 00:00 UTC with 1-second timestep to achieve numerical stability. Utilizing parallel computing on an 8 -core, $2.80 \mathrm{GHz}$ Intel ${ }^{\circledR}$ Core $^{\mathrm{TM}} \mathrm{i} 7-7700 \mathrm{HQ}$ processor, the simulation ran for only 2 hours and 30 minutes. Text-based output files were post-processed using custom MATLAB scripts and converted to Google Earth Pro format using OpenEarthTools. 


\section{RESULTS}

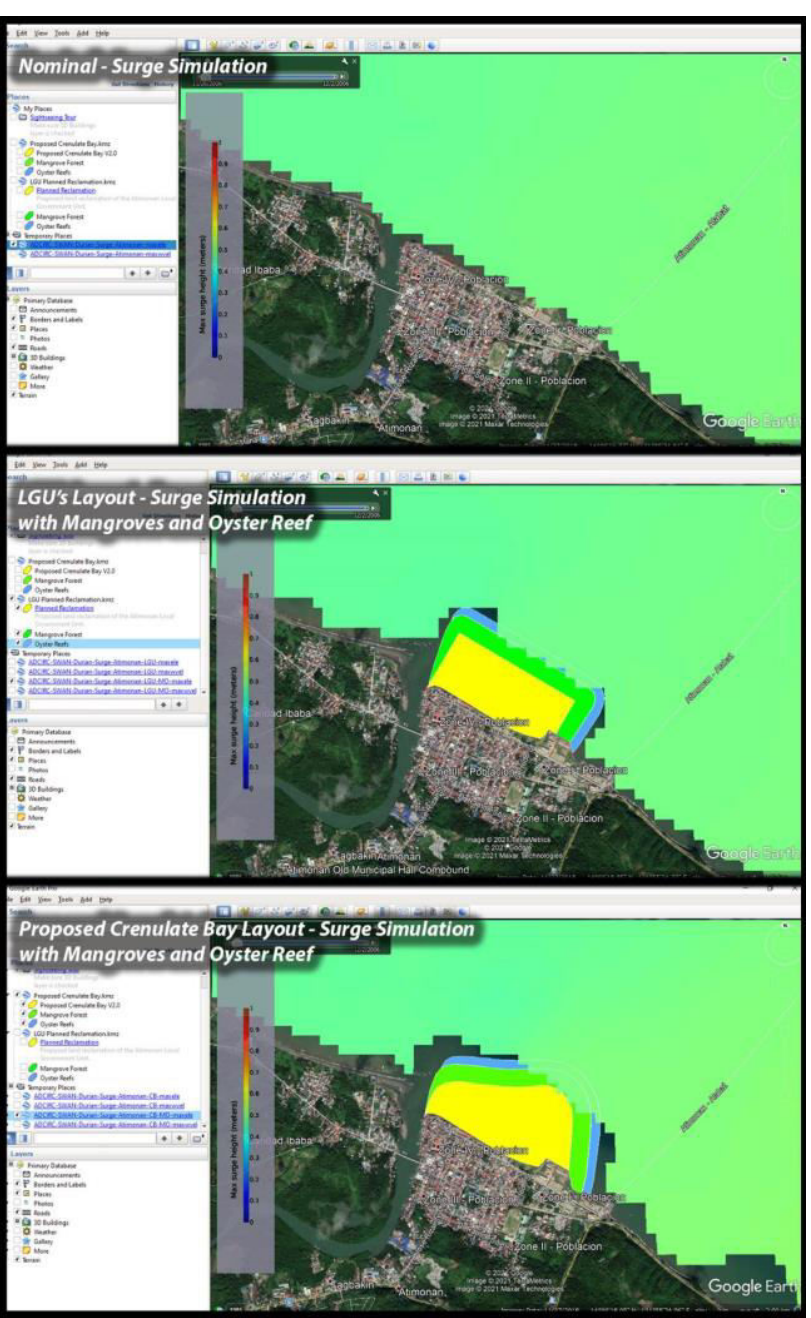

Figure 11. Simulated maximum surge height and inundation extent induced by Typhoon Durian on Atimonan. From top to bottom: nominal (no reclamation), LGU plan, crenulate bay plan.

The nominal simulation confirmed the reports of the locals that they only experienced flooding of around 1 foot, and barely reached the residential buildings along the shoreline (see Figure 11). The presence of a barrier island, located far Northeast of the study area, weakened the local wind field of the typhoon. All simulations experience similar surge height and relatively stronger winds on the northeast area, to which the Atimonan LGU should pay attention.

Both mangrove areas on both scenarios were inundated by surge, with the LGU plan being less affected. In the crenulate bay scenario, the seawater is already at the edge of the built-up area. The curve at the northeast portion of the crenulate bay is too sharp that it faces the waves head-on. Substantial reduction of typhoon winds was also established on both scenarios (see Figure 12), with areas in the crenulate bay plan experienced gentler winds that extend to the City Center. In terms of the land area affected by winds and surge, the crenulate bay plan generated a smaller area by $39.15 \%$ than the LGU plan. However, this advantage comes with an additional implementation cost of $11.02 \%$.

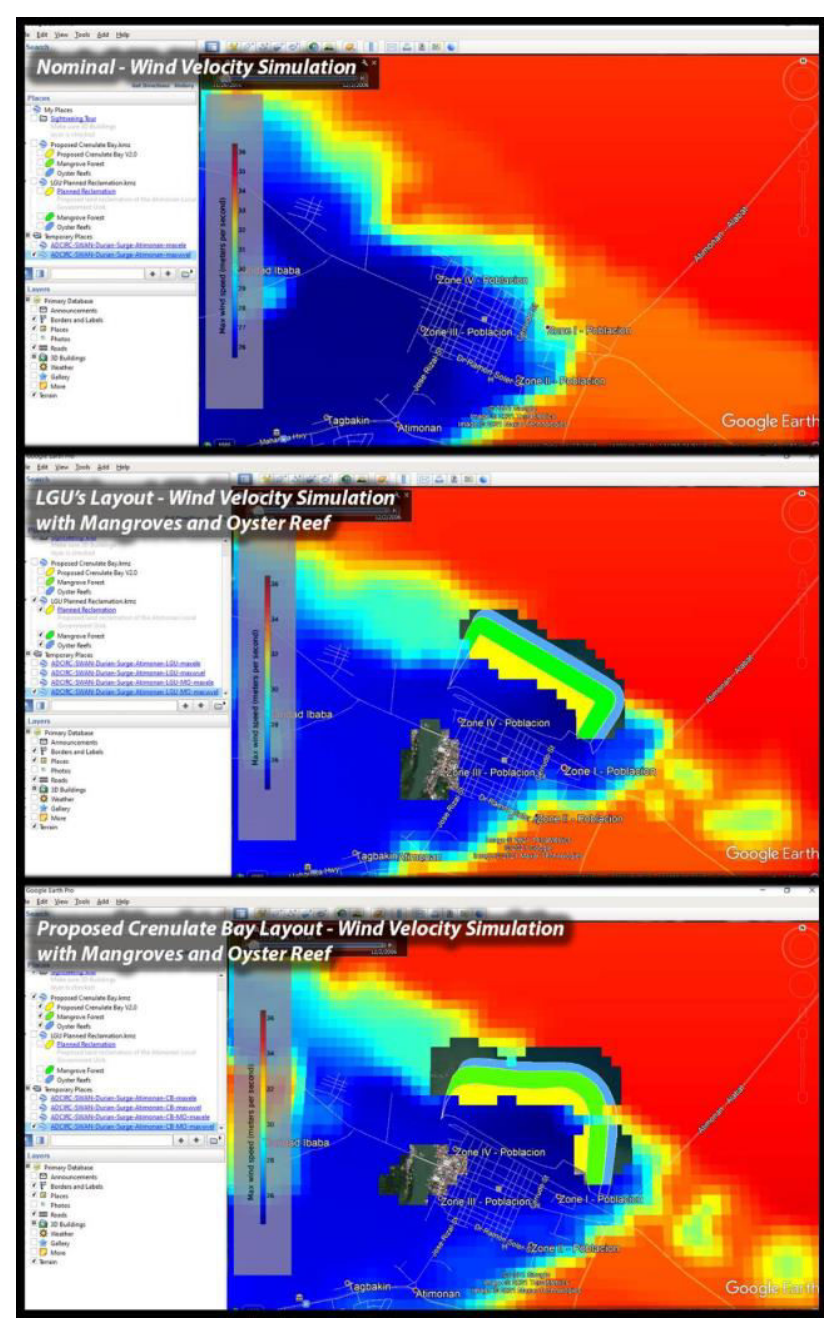

Figure 12. Simulated maximum wind speed induced by Typhoon Durian simulated on Atimonan. From top to bottom: nominal (no reclamation), LGU plan, crenulate bay plan.

\section{CONCLUSION}

The Municipality of Atimonan is rapidly developing with necessary addition of infrastructure and facilities to bring government services more accessible to the local community. Surrounded by mountainous terrain with steep slopes unsuitable for construction, the Local Government Unit proposed a Town Expansion Development Program that involves the reclamation of the coastal area to provide ample space to construct modern infrastructure for social and economic purposes.

Mangrove species, oyster reefs and concrete seawall can be utilized for coastal protection and stabilization, as well as reducing the impact of tropical storms in the proposed reclamation scenarios. The shape of the crenulate bay was derived from the predicted long-term behavior of the coastline, while the mangrove species zonation was based on the environmental assessment during the site visit.

The resiliency of hypothetical land reclamation scenarios against typhoons were tested in a storm surge model. The ADCIRC and SWAN coupled model produced meaningful storm surge simulations that successfully integrated the hypothetical land reclamation scenarios envisioned in this study. It is important to note that the accuracy of the simulation depends on the quality of the input data. The mangrove forests 
and oyster reefs successfully reduced typhoon winds and coastal inundation extent. Mangrove forests protects the water surface from wind stress and together with oyster reefs, reduces energy of waves as it travels nearshore.

By having a smaller area affected by surge and winds, the crenulate bay was proved to be a better reclamation plan for Atimonan LGU. It is up to the LGU if they are willing to shoulder additional cost to implement the crenulate bay plan. With this approach, land reclamation projects can be better analysed by land developers and government agencies for effective urban planning and disaster risk reduction while protecting the coastal environment.

\section{ACKNOWLEDGEMENTS}

The authors would like to thank the Atimonan Local Government Administration, as well as the Municipal Environment and Natural Resources Office for the permission and assistance on site visit, data gathering, mangrove forest river cruise, and aerial photography of the study area conducted on March 2020

\section{REFERENCES}

Brandon, C., Woodruff, J., Orton, P., and Donnelly, J. 2016. Evidence for elevated coastal vulnerability following largescale historical oyster bed harvesting. Earth Surface Processes and Landforms 41(8), 1136-1143. doi.org/10.1002/esp.3931

Chowdhury, M., Walles, B., Sharifuzzaman S., Shahadat Hossain, M., Ysebaert T., Smaal, A. 2019. Oyster breakwater reefs promote adjacent mudflat stability and salt marsh growth in a monsoon dominated subtropical coast. Sci Rep 9(8549). doi.org/10.1038/s41598-019-44925-6

Egbert, G., and Erofeeva, S., 2002. Efficient Inverse Modeling of Barotropic Ocean Tides. Journal of Atmospheric and Oceanic Technology 19(2), 183-204. doi.org/10.1175/15200426(2002)019<0183:EIMOBO>2.0.CO;2

Giri, C., Ochieng, E., Tieszen, L., Zhu, Z., Loveland, T., Masek, J., and Duke, N. 2010. Status and distribution of mangrove forests of the world using earth observation satellite data. Global Ecology and Biogeography 20(1), 154-159. doi.org/10.1111/j.1466-8238.2010.00584.x

Grabowski, J., Brunbaugh, R., Conrad, R., et. al. 2012. Economic Valuation of Ecosystem Services Provided by Oyster $\begin{array}{lll}\text { Reefs. } & \text { BioScience } & \text { 600-909. }\end{array}$ doi.org/10.1525/bio.2012.62.10.10

Hope, M., Westerink, J., Kennedy, P., et. al. 2013. Hindcast and validation of Hurricane Ike (2008) waves, forerunner, and storm surge. Journal of Geophysical Research: Oceans 118(9), 4424-4460. doi.org/10.1002/jgrc.20314

Livingston, R., Howell, R., Niu, X., Lewis, F., and Woodsum, G. 1999. Recovery of oyster reefs (Crassostrea virginica) in a gulf estuary following disturbance by two hurricanes. Bulletin of Marine Science 64(3), 465-483. Retrieved from https://www.ingentaconnect.com/content/umrsmas/bullmar/199 9/00000064/00000003/art00006
Luettich, R., Westerink, J., and Scheffner, N. 1992. ADCIRC: an advanced three-dimensional circulation model for shelves coasts and estuaries. Retrieved from https://adcirc.org/wpcontent/uploads/sites/2255/2018/11/1992_Luettich02.pdf

Mattocks, C., and Forbes, C., 2008. A real-time, event-triggered storm surge forecasting system for the state of North Carolina. Ocean Modelling, 25, 95-119. doi.org/ 10.1016/j.ocemod.2008.06.008.

Morris R., Boxshall A., and Swearer S. 2020. Climate-resilient coasts require diverse defence solutions. Nature Climate Change 10, 485-487. doi.org/10.1038/s41558-020-0798-9

Nadzhirah, M., Ibrahim, M., and Mansor, M., 2014. Impacts of Coastal Reclamation to the Quality of Life: Tanjung Tokong community, Penang. Procedia - Social and Behavioral Sciences, 153, 159-168. doi.org/ 10.1016/j.sbspro.2014.10.050.

Orinday, R., 2019. DENR tours media to selected protected areas in Quezon. Retrieved from: https://pia.gov.ph/news/articles/1026918

Reeve, D., Chadwick, A., Fleming, C., 2014. Coastal Engineering: Processes, Theory and Design Practice. CRC Press. ISBN: 9781138060432

Roberts, K., Pringle, W., and Westerink, J., 2019. OceanMesh2D 1.0: MATLAB-based software for twodimensional unstructured mesh generation in coastal ocean modeling. Geoscientific Model Development, 12, 1847-1868. doi.org/10.5194/gmd-12-1847-2019.

Saenger, P., and Siddiqi, N. 1993. Land from the sea: The mangrove afforestation program of Bangladesh. Ocean and Coastal Management 20(1), 23-39. doi.org/10.1016/09645691(93)90011-M

Spalding, M., Mclvor, A., Tonneijck, F., Tol, S., \& van Eijk, P. 2014. Mangroves for coastal defence: Guidelines for coastal managers \& policy makers. Retrieved from https://www.nature.org/media/oceansandcoasts/mangroves-forcoastal-defence.pdf

Sutton-Grier, A., Wowk, K., and Bamford, H. 2015. Future of our coasts: The potential for natural and hybrid infrastructure to enhance the resilience of our coastal communities, economies and ecosystems. Environmental Science and Policy 51, 137-148. doi.org/10.1016/j.envsci.2015.04.006.

United Nations Office for the Coordination of Human Affairs. 2016. Philippines Typhoon Appeal 2006. Retrieved from https://www.humanitarianresponse.info/en/programmecycle/space/document/philippines-typhoon-appeal-2006

Weatherall, P., Marks, K., Jakobsson, M., et. al. 2015. A new digital bathymetric model of the world's oceans. Earth and Space Science 2(8), 331-345. doi.org/10.1002/2015EA000107 